\title{
Conditioned Contribution of Peripheral Cocaine Actions to Cocaine Reward and Cocaine-Seeking
}

\author{
Bin Wang', Zhi-Bing You', Erik B Oleson², Joseph F Cheer², Stephanie Myal' and Roy A Wise*,' \\ 'Behavioral Neuroscience Branch, Intramural Research Program, National Institute on Drug Abuse, National Institutes of Health, \\ Department of Health and Human Services, Baltimore, MD, USA; ${ }^{2}$ University of Maryland School of Medicine Department of Anatomy and \\ Neurobiology Baltimore, MD, USA
}

\begin{abstract}
Cocaine has actions in the peripheral nervous system that reliably precede - and thus predict-its soon-to-follow central rewarding effects. In cocaine-experienced animals, the peripheral cocaine signal is relayed to the central nervous system, triggering excitatory input to the ventral tegmental origin of the mesocorticolimbic dopamine system, the system that mediates the rewarding effects of the drug. We used cocaine methiodide, a cocaine analog that does not cross the blood-brain barrier, to isolate the peripheral actions of cocaine and determine their central and behavioral effects in animals first trained to lever-press for cocaine hydrochloride (the centrally acting and abused form of the drug). We first confirmed with fast-scan cyclic voltammetry that cocaine methiodide causes rapid dopamine release from dopamine terminals in cocaine hydrochloride-trained rats. We then compared the ability of cocaine hydrochloride and cocaine methiodide to establish conditioned place preferences in rats with self-administration experience. While cocaine hydrochloride established stronger place preferences, cocaine methiodide was also effective and its effectiveness increased (incubated) over weeks of cocaine abstinence. Cocaine self-administration was extinguished when cocaine methiodide or saline was substituted for cocaine hydrochloride in the intravenous self-administration paradigm, but cocaine hydrochloride and cocaine methiodide each reinstated nonrewarded lever-pressing after extinction. Rats extinguished by cocaine methiodide substitution showed weaker cocaine-induced reinstatement than rats extinguished by saline substitution. These findings suggest that the conditioned peripheral effects of cocaine can contribute significantly to cocaine-induced (but not stress-induced) cocaine craving, and also suggest the cocaine cue as an important target for cue-exposure therapies for cocaine addiction.

Neuropsychopharmacology (2013) 38, 1763-1769; doi:I0.1038/npp.2013.75; published online 17 April 2013
\end{abstract}

Keywords: cocaine; reward; self-administration; peripheral actions; dopamine; reinstatement

\section{INTRODUCTION}

Cocaine hydrochloride $(\mathrm{HCl})$ has multiple central and peripheral actions. It is the drug's central actionsprimarily the ability to block dopamine reuptake in the forebrain (Thomsen et al, 2009a, b) - that are responsible for its unconditioned rewarding effects and abuse liability (de Wit and Wise, 1977; Risner and Jones, 1980; Roberts et al, 1977). However, its peripheral actions, because they reliably precede (and thus predict) the rewarding central action of the drug, become conditioned stimuli for excitatory input to the reward system (Wise et al, 2008) and, in experienced users, have the potential to contribute to the net rewarding effect of cocaine (You et al, 2007). Because they activate the reward system first, the peripheral

*Correspondence: Dr RA Wise, Behavioral Neuroscience Branch, Intramural Research Program, National Institute on Drug Abuse, National Institute on Drug Abuse, National Institutes of Health, Department of Health and Human Services, 5500 Nathan Shock Drive, 25I Bayview Boulevard, Baltimore, MD 21224, USA, Tel: + I 443740 2460, Fax: + I 4437402827 ,

E-mail: rwise@intra.nida.nih.gov

Received 2 February 20 I3; revised 13 March 2013; accepted 13 March 2013; accepted article preview online 27 March 2013 actions of cocaine are suggested to become the initial segment of cocaine's net rewarding effects in experienced users (Wise and Kiyatkin, 2011b). Because the effectiveness of rewards depends in large part on their immediacy (Renner, 1964; Fouriezos and Randall, 1997), the conditioned peripheral effects of the drug may contribute importantly to why repeated cocaine use becomes increasingly compulsive (Wise and Kiyatkin, 2011a).

In this study, we used cocaine methiodide (MI), a cocaine analog that does not cross the blood-brain barrier (Wise et al, 2008), to differentiate the peripheral and central effects of cocaine in animals trained to self-administer intravenous cocaine $\mathrm{HCl}$ (the addictive form) by lever-pressing. In cocaine $\mathrm{HCl}$-trained rats, we assessed the ability of cocaine MI to cause conditioned dopamine release in nucleus accumbens and to serve as a conditioned reward in a conditioned place-preference experiment. We also determined the relative effects on the lever-pressing habit of substituting cocaine $\mathrm{MI}$ or saline for cocaine $\mathrm{HCl}-\mathrm{a}$ form of 'cue-exposure' therapy (Marlatt, 1990)_in animals trained to self-administer cocaine $\mathrm{HCl}$. Finally, we assessed the relative effectiveness of systemic cocaine MI and cocaine $\mathrm{HCl}$ injections to reinstate non-rewarded responding-a 
presumed measure of cue-induced cocaine craving (Grimm et al, 2001) - following each of the extinction conditions.

\section{MATERIALS AND METHODS}

\section{Subjects}

Ninety-two 350-400g male Long-Evans rats (Charles River, Raleigh, NC) were used. They were housed individually under a reverse light/dark cycle (light on from 2000 hours to 0800 hours) with ad libitum access to food and water and were allowed to acclimate to the new environment for at least 7 days before surgery. All experimental procedures followed the Guide for the Care and Use of Laboratory Animals published by National Institutes of Health (1996). The voltammetry study was carried out at the University of Maryland and was approved by the University of Maryland Animal Care and Use Committee; all other studies were carried out at the Intramural Research Program of the National Institute on Drug Abuse and were approved by its Animal Care and Use Committee.

\section{Surgery}

Before the place-preference, extinction and reinstatement studies, each rat was implanted, under a mixture of pentobarbital $(30 \mathrm{mg} / \mathrm{kg}$, intraperitoneally) and chloral hydrate $(140 \mathrm{mg} / \mathrm{kg}$, intraperitoneally) anesthesia, with an intravenous Silastic catheter (Dow Corning, Midland, MI) in the right external jugular vein. The catheter was inserted to just penetrate the right atrium and was secured to the vein with silk suture. The end of the catheter was fed subcutaneously around the back of the neck to exit at the back of the skull, where it was seated on a 22-G stainlesssteel cannula (Plastics One, Roanoke, VA) fixed to the head assembly with stainless-steel skull screws and dental cement. Each rat was given subcutaneous injections of $0.25 \mathrm{ml}$ of $2.27 \%$ enrofloxacine (Baytril) following surgery and daily for the next 2 days. The catheters were flushed daily with $0.05 \mathrm{ml}$ of gentamicin $(4 \mathrm{mg} / \mathrm{ml}$ in sterile saline) and $0.1 \mathrm{ml}$ of heparinized saline $(10 \mathrm{U} / \mathrm{ml}$ in sterile saline) before and after testing.

\section{Self-Administration Training}

With the exception of one group of rats that served as a control group in the conditioned place-preference task, the rats for each experiment were first trained to self-administer intravenous cocaine $\mathrm{HCl}$. Training was daily in 4 -h sessions over 14 consecutive days. After recovery from surgery, the catheter of each animal was connected by polyethylene tubing through a fluid swivel to a syringe in a microprocessor-controlled syringe pump (Razel Scientific Instruments, Stamford, CT). The animal was placed in an operant chamber equipped with two levers positioned side-by-side $9 \mathrm{~cm}$ above a grid floor connected to a shock generator and polarity scrambler. Each rat was trained to press one of the levers ('active' lever) for intravenous cocaine $\mathrm{HCl}(1 \mathrm{mg} / \mathrm{kg}$ per injection, delivered in a volume of $0.13 \mathrm{ml}$ over $4.5 \mathrm{~s}$ ) on a fixed ratio-1 schedule of reinforcement; each injection triggered illumination of cue light above the lever. A 20-s timeout period, in which the cue light remained on and additional lever-pressing was ineffective, was initiated with each drug injection. For the last three training sessions, the mean number of responses on the active lever was $45.1 \pm 12.3$; the mean number on the other, 'inactive', lever was $2.5 \pm 1.9$; the mean number of injections earned was $35.9 \pm 2.8$. The cocaine-naive control group destined for the subsequent place-preference study was similarly prepared and handled but received unearned saline rather than earned cocaine injections throughout the training period. In this group, the timing of each animal's injections was yoked to those earned by a partner in the self-administration group. Illumination of the house light accompanied the onset of these yoked injection sessions, and the cue light was illuminated for $20 \mathrm{~s}$ with the onset of each saline injection. Thus, this group received the same handling and the same exposure to equipment, context, and unconditioned cues as did the normally trained animals, but for this group these cues were never associated with cocaine injections. The cocaine-trained animals all reached the criterion of stability of $<10 \%$ variance in intake over the last 3 days of training and were assigned randomly groups. The mean cocaine intakes for the various groups on the last training day ranged from 35.5 to $37.9 \mathrm{mg} / \mathrm{kg}$ (SEMs: $0.8-2.8$ ). Cocaine intake over the last 5 days of training ranged from 175 to $189 \mathrm{mg} / \mathrm{kg}$ per rat (SEMs 7.1-14.0). The total cocaine intake over the entire 2 weeks of training ranged between groups from 416 to $484 \mathrm{mg} / \mathrm{kg}$ per rat (SEMs 19.6-36.8).

\section{Conditioned Place Preference}

Cocaine-conditioned place preference was tested in a onetrial conditioning procedure under two regimens. In the first regimen, four groups were tested $24 \mathrm{~h}$ after the last cocaine self-administration or yoked saline session. Three of these groups had previously self-administered cocaine $\mathrm{HCl}$; one of the three $(n=14)$ was conditioned with an intraperitoneal injection of cocaine $\mathrm{HCl}(10 \mathrm{mg} / \mathrm{kg})$, one group $(n=10)$ with an equimolar intraperitoneal injection of cocaine MI $(13 \mathrm{mg} / \mathrm{kg})$, and one group $(n=6)$ was 'conditioned' with an equal intraperitoneal volume of physiological saline. The fourth group in this regimen $(n=10)$ was the previously mentioned cocainenaive control group that received saline injections in the training phase and was given intraperitoneal cocaine MI $(13 \mathrm{mg} / \mathrm{kg})$ here in the place-conditioning task. The second regimen involved three additional groups of rats $(\mathrm{NS}=9$, 10 , and12) for which place conditioning was carried out 7 , 15 , or 30 days, respectively, after the last day of cocaine selfadministration training.

The place-conditioning apparatus (Med Associates, St Albans, VT) consisted of two compartments $\left(21 \times 28 \mathrm{~cm}^{2}\right)$ linked by a gray connecting area $\left(21 \times 12.5 \mathrm{~cm}^{2}\right)$; a sliding door separated each compartment from the connecting area. The two end compartments differed in wall color (black $v s$ white), floor type (net $v s$ grid), and illumination; preference for the end compartments was balanced by using weaker illumination in the reflective (and normally lesspreferred) white compartment and stronger illumination in the non-reflective black compartment. The paradigm was further 'balanced' by associating the training injections with 
the white side in half the animals and with the black side in the remaining animals.

On the day of place conditioning, the rats in various conditions were given intraperitoneal injections of cocaine $\mathrm{HCl}(10 \mathrm{mg} / \mathrm{kg})$, cocaine $\mathrm{MI}(13 \mathrm{mg} / \mathrm{kg})$, or saline; each rat was then confined to its assigned compartment for 15 min. Place preference was determined on a subsequent day. Each rat was placed (without any injection) for $5 \mathrm{~min}$ in the connecting area of the chamber; then, the doors to two end chambers were opened and the times spent in each of the three compartments were recorded. The animals were removed after $15 \mathrm{~min}$ of free choice between chambers. The chambers were wiped clean with a Nolvasan solution and $70 \%$ alcohol between trials. The one-trial-conditioning procedure was used because, if effective, cocaine MI was expected to be a conditioned reinforcer. Inasmuch as conditioned reinforcers lose effectiveness each time they are given in the absence of their unconditioned counterpart, multiple-conditioning trials would have caused progressive degrading of any rewarding effects of cocaine MI.

\section{Extinction and Reinstatement}

An additional 22 self-administration-trained rats were subjected to extinction 'training' and used in subsequent reinstatement tests. Here, after normal self-administration training, the animals were given 14-27 further $4 \mathrm{~h}$ leverpressing sessions in which saline $(0.13 \mathrm{ml}$ per injection: $n=10)$ or cocaine MI $(1.3 \mathrm{mg} / \mathrm{kg}$ per infusion: $n=12)$ was substituted for cocaine HCl. Each animal's sessions continued until its active-lever response counts decreased, for three consecutive days, to fewer than four responses per hour (16 responses per 4-h session); this was the baseline level of responding seen in untrained animals allowed to explore and manipulate the apparatus.

Following completion of the extinction trials, two subgroups of the extinguished rats, one that had received saline extinction $(n=5)$ and one that had received cocaine MI extinction $(n=6)$, were tested for drug-induced reinstatement of the lever-pressing response. For these tests the rats were housed with food and water in their operant chambers starting the day before 2 days of repeated reinstatement testing. On one of the two test days, each rat was given a series of 'priming' injections involving saline, $5 \mathrm{mg} / \mathrm{kg}$ of cocaine $\mathrm{HCl}$, and $10 \mathrm{mg} / \mathrm{kg}$ of cocaine $\mathrm{HCl}$; on the other day, it was given a series involving saline, $6.5 \mathrm{mg} / \mathrm{kg}$ of cocaine MI, and $13 \mathrm{mg} / \mathrm{kg}$ cocaine MI. Half the animals got the $\mathrm{HCl}$ series first and half got the MI series first. The three tests on each day were given at 2-h intervals; for each test the animal was lifted from the testing chamber, given the scheduled intraperitoneal injection, and returned to the chamber to start the test. Lever-pressing was recorded for $2 \mathrm{~h}$ after each injection.

The remaining rats from the extinction testing were used to determine the effect of mild footshock stress on leverpressing under continued extinction conditions; one subgroup had received saline extinction $(n=5)$ and the other had received cocaine MI extinction $(n=6)$. Just before insertion of the response lever, each rat was given a 20-min series of scrambled, inescapable, and unpredictable 0.5-s footshocks, administered at random intervals ranging from
10 to $70 \mathrm{~s}$ at an intensity just sufficient to cause forward locomotion and sniffing (below the level that would cause behavioral arrest or 'freezing' in each animal). The appropriate shock intensity was determined for each animal the afternoon before the reinstatement test; shock intensity ranged from 0.3 to $0.6 \mathrm{~mA}$. Footshock was followed by another 2-h extinction session.

\section{Fast-Scan Cyclic Voltammetry}

Five rats were fitted with jugular vein catheters and used as subjects for fast-scan cyclic voltammetry. They were trained to lever-press for intravenous cocaine $\mathrm{HCl}(0.75 \mathrm{mg} / \mathrm{kg}$ intravenously) under a fixed-ratio 1 schedule of reinforcement over ten 2-h daily sessions. Following training, each rat was anesthetized with isoflurane and implanted with a guide cannula above the nucleus accumbens shell $(+1.7$ $\mathrm{AP} ;+0.8 \mathrm{ML})$, an ipsilateral bipolar stimulating electrode in the ventral tegmental area (VTA: $-5.4 \mathrm{AP} ;+0.5 \mathrm{ML}$; and $-8.7 \mathrm{DV}$ ) and a contralateral $\mathrm{Ag} / \mathrm{AgCl}$ reference electrode. On a subsequent test day, a micromanipulator was connected to the guide cannula and used to lower a carbon fiber electrode into the nucleus accumbens shell of the awake, freely moving, animal. Dopamine was detected from fast-scan cyclic voltammograms collected at the carbon fiber every $100 \mathrm{~ms}$ (initial triangle waveform: potential from -0.4 to $1.3 \mathrm{~V} v s$ an $\mathrm{Ag} / \mathrm{AgCl}$ reference, $400 \mathrm{~V} / \mathrm{s}$ ). After optimization of recording site during electrical stimulation of the VTA, 15 consecutive $60 \mathrm{~s}$ files were collected sequentially for each component of the experiment; these consisted of baseline, vehicle injection (sterile saline, intravenously), cocaine MI injection ( $1.25 \mathrm{mg} / \mathrm{kg}$ intravenously), and cocaine $\mathrm{HCl}$ injection $(1.0 \mathrm{mg} / \mathrm{kg}$ intravenously). Dopamine concentration was estimated from raw voltammetric data using principal component regression and postexperimentally determined scaling factors for dopamine and $\mathrm{pH}$. To verify recording sites, rats were again anesthetized and a high amplitude current $(500 \mu \mathrm{A})$ was applied through a stainless-steel electrode lowered to the recording site. The rats were then intracardially perfused with saline, potassium ferrocyanide stain, and $10 \%$ formalin. The brains were removed, cryoprotected, and coronal frozen sections were taken for light microscopic examination.

\section{RESULTS}

Fast-scan cyclic voltammetry confirmed that cocaine MI and cocaine $\mathrm{HCl}$ each induced a short-latency increase in transient dopamine release in the nucleus accumbens shell region of animals previously trained with cocaine $\mathrm{HCl}$ (Figure 1). Equimolar doses of cocaine $\mathrm{HCl}$ were more effective than cocaine $\mathrm{MI}$ in increasing dopamine transients. Cocaine MI does not induce NAS dopamine transients in cocaine-naive animals (Porter-Stransky et al, 2011).

All rats quickly learned to lever-press for intravenous cocaine $\mathrm{HCl}$; cocaine intake did not differ significantly between the six groups of rats tested in behavioral experiments. By the end of the 2-week training period, all animals were responding for $1 \mathrm{mg} / \mathrm{kg}$ injections of cocaine $\mathrm{HCl}$ at rates of approximately 10-12 lever-presses per hour. In cocaine $\mathrm{HCl}$-trained animals, intraperitoneal cocaine $\mathrm{HCl}$ 


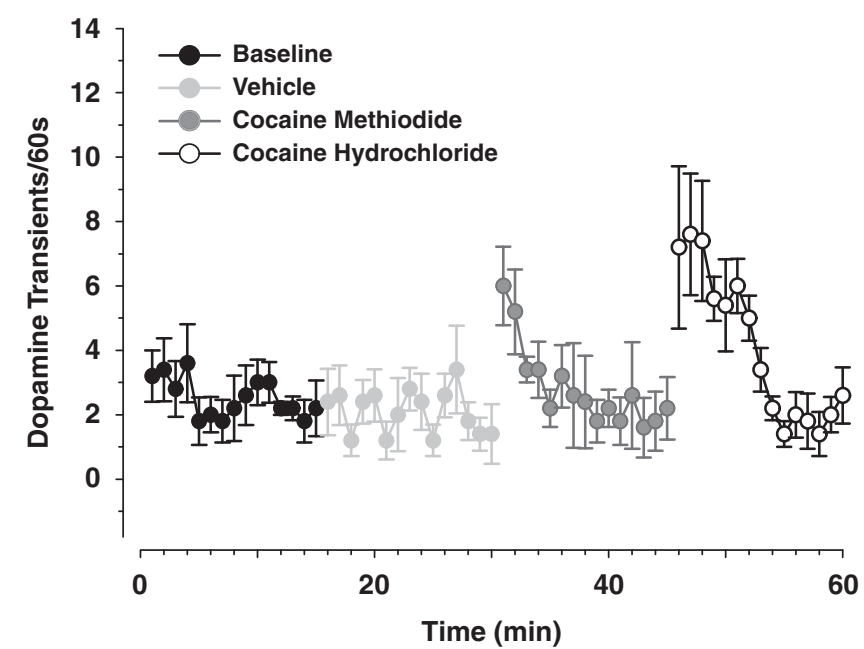

Figure I Effects of saline, cocaine methiodide, and cocaine hydrochloride on dopamine transients as measured in nucleus accumbens by fastscan cyclic voltammetry in rats previously trained to self-administer intravenously cocaine hydrochloride.

established a strong conditioned preference for the drugassociated chamber (over $450 \mathrm{~s}$ out of 900 ; Figure 2, column 1), whereas saline failed to do so (Figure 2, column 2). The saline-treated animals spent equal time in the salineassociated (334 $\pm 37 \mathrm{~s})$ and the novel $(338 \pm 40 \mathrm{~s})$ end chambers, slightly less time in the familiar $(226 \pm 32 \mathrm{~s})$ connecting chamber. Equimolar injections of cocaine MI given to cocaine-naive animals (animals that had not received the prior training with cocaine $\mathrm{HCl}$ ) was ineffective; it failed to increase preference for the drug-associated compartment (Figure 2, column 3). However, cocaine MI given to the initial group of cocaine-experienced animals significantly, although modestly, increased preference for the drug-associated compartment (Figure 2, column 4). In the animals given place conditioning 7, 15, or 30 days after the last day of self-administration training, the increases in preference were stronger (Figure 2, columns 5-7), approaching the strength of preferences conditioned with cocaine $\mathrm{HCl}$ on the first day after training (Figure 2, column 1). In the 15-day withdrawal condition, absolute place preference was established, with the animals spending more time $(509 \pm 22.4 \mathrm{~s})$ in the drug-associated chamber than in the novel end chamber $(205 \pm 16.5 \mathrm{~s})$ and the familiar connecting chamber $(182 \pm 16.3)$ combined. In general, increased time spent on the drug-associated chamber came at the expense of time spent in the other end chamber; time in the former was negatively and almost perfectly correlated with time in the latter $(r=-0.983)$. The time in neutral connecting chamber correlated weakly and negatively with time in the drug-associated chamber $(r=-0.598)$, and correlated weakly and positively with time in the neutral end chamber $(r=0.453)$. Time spent in the connecting chamber was always less $(\sim 200 \mathrm{~s})$ than $1 / 3$ of the time available; time spent in neutral end chamber was also less than $1 / 3$ of the time available, except in the two control conditions (cocaine-experienced animals given saline and cocaine-naive animals given cocaine MI; Figure 2).

Lever-pressing decreased progressively ('extinguished') when saline or cocaine MI was substituted for cocaine $\mathrm{HCl}$

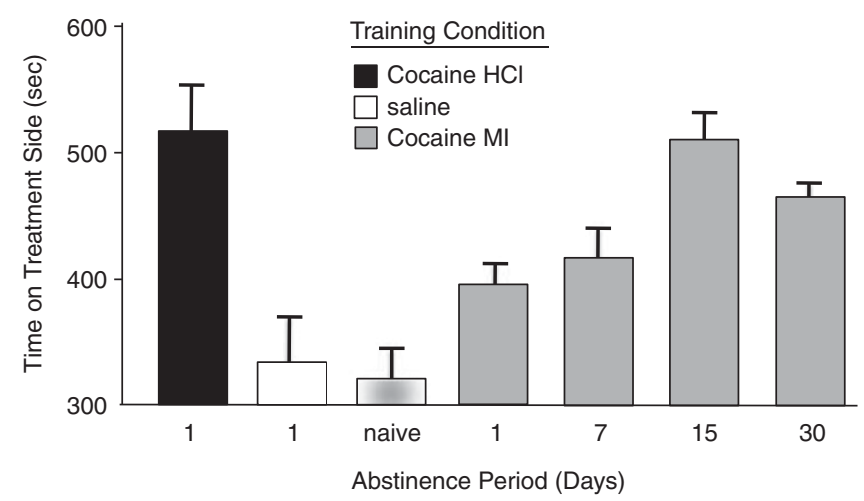

Figure 2 Times spent in the drug-associated chamber in the conditioned place-preference tests. Total time for the test was $900 \mathrm{~s}$. Cocaine hydrochloride $(\mathrm{HCl})(10 \mathrm{mg} / \mathrm{kg}$, intraperitoneally), cocaine methiodide (MI) $(13 \mathrm{mg} / \mathrm{kg}$, intraperitoneally) or saline were given on the conditioning days $1,7,15$, or 30 days after cocaine $(\mathrm{HCl})$ self-administration training. Column 3 data ('naive') are from a group that were conditioned with cocaine $\mathrm{Ml}$ but had no prior experience with cocaine $\mathrm{HCl}$. Analysis of variance across the four groups tested after one day of abstinence (columns $1-4$ in the figure) showed a significant effect of Group $\left(F_{3,30}=18.26\right.$, $P<0.000 \mathrm{I}$ ) with significant differences between groups conditioned with cocaine $\mathrm{HCl}$ and saline $(t=4.828, \quad P<0.000 \mathrm{I})$ and cocaine-naive vs cocaine-experienced groups conditioned with cocaine $\mathrm{Ml}(t=3.63$, $P<0.00$ I). Analysis of variance across the four cocaine-experienced groups that were conditioned with cocaine $\mathrm{MI}$ (columns 4-7 in the figure) showed a significant effect of Group $\left(\mathrm{F}_{3,37}=7.182, \mathrm{P}<0.00 \mathrm{I}\right)$ and a significant linear trend $\left(F_{3,37}=13.803, P<0.00 I\right)$ with insignificant evidence of a quadratic trend $\left(F_{3,37}=3.282, P<0.0782\right)$.

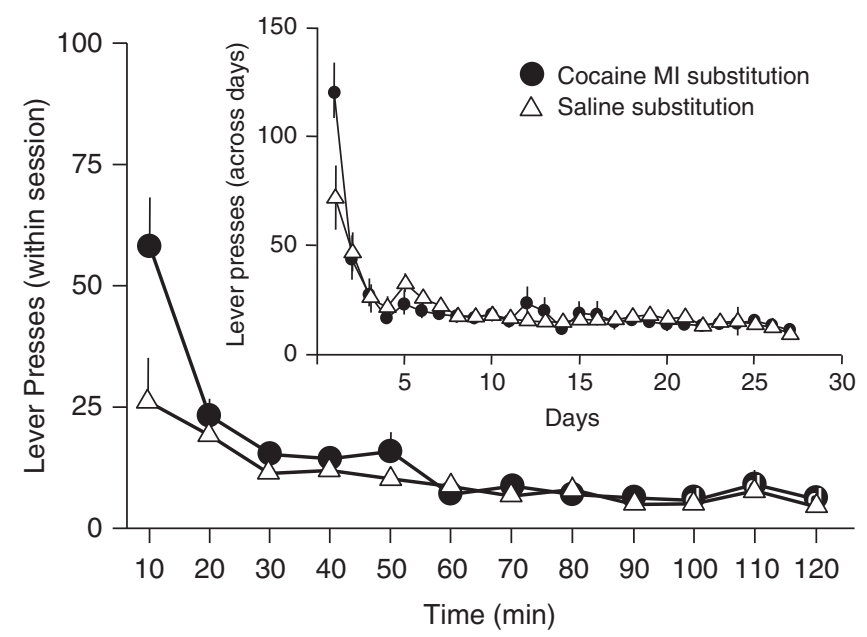

Figure 3 Responding for cocaine methiodide (MI) or saline following self-administration training with cocaine hydrochloride $(\mathrm{HCl})$. The primary graph shows responding on the first day of cocaine $\mathrm{Ml}$ or saline substitution; the inset shows mean daily responding for all animals through the first 14 days and, for subsequent days, mean responding for the animals that had not yet reached the extinction criterion. Analysis of variance showed significant decreases in responding over time both within the first session $\left(F_{1 \mid, 240}=8.865, P<0.000 I\right)$ and across $\left(F_{26,379}=18.62, \quad P<0.000 I\right)$ sessions. Planned t-tests showed significantly higher responding for the animals extinguished with cocaine $\mathrm{Ml}$ in the first $10 \mathrm{~min}\left(t_{5}=3.9\right.$, $P<0.000 \mathrm{I})$ and across the first day $\left(t_{5}=6.8, P<0.00 \mathrm{I}\right)$ of extinction testing; no such difference was statistically reliable on subsequent days.

(Figure 3). Rats that were switched to cocaine MI or saline each continued to lever-press at higher than baseline levels for about 3 weeks (19.0 \pm 1.23 and $20.2 \pm 1.5$ days, 


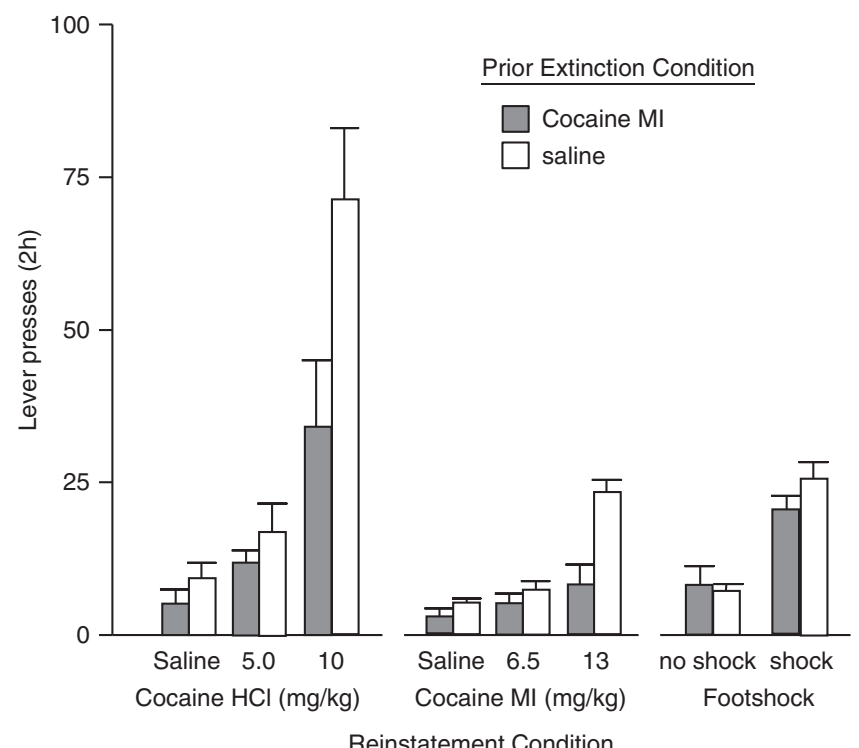

Figure 4 Renewed lever-pressing for saline by cocaine hydrochloride $(\mathrm{HCl})$, cocaine methiodide $(\mathrm{MI})$, or mild footshock stress following extinction training with saline or cocaine MI. Analysis of variance for the priming experiment showed significant effects of extinction condition $\left(F_{1,40}=8.287, P<0.02\right)$, priming dose $\left(F_{5,40}=29.24, P<0.000 I\right)$, and the interaction $\left(F_{5.40}=4.139, P<0.004\right)$. Analysis of variance for the footshock experiment showed a significant effect of footshock $\left(F_{1,18}=36.58\right.$, $P<0.000$ I) but no significant interaction of footshock with prior extinction condition $\left(F_{1,9}=0.2667, P>0.25\right)$.

respectively). While the rats switched to cocaine MI initially responded more than those switched to saline, the difference was largely restricted to the early minutes of the first day of extinction testing; there was no significant difference between the responding of the cocaine MI and saline groups after the first day of testing.

Following 3 weeks of extinction training in which saline or cocaine MI was substituted for the cocaine $\mathrm{HCl}$ used in training, dose-orderly renewal of non-rewarded leverpressing was induced by priming injections of either cocaine $\mathrm{HCl}$ or of cocaine MI. In these tests, the rats that had undergone extinction training with cocaine MI responded significantly less than the animals that had undergone extinction training with saline (Figure 4). Unrewarded lever-pressing was also renewed following mild footshock stress; in this case, there was no statistically reliable difference between the renewed responding of animals that had undergone extinction trials with cocaine MI and that of the animals that had undergone extinction with saline (Figure 4).

\section{DISCUSSION}

Our primary findings were that a peripheral action of cocaine-triggered selectively by cocaine MI, a cocaine analog that does not cross the blood-brain barrier-activates the reward system and serves as a conditioned reinforcer in cocaine-experienced but not cocaine-naive rats. Previous work had shown that cocaine MI activates glutamatergic input to the midbrain dopamine system and causes dendritic release of dopamine in the VTA (Wise et al, 2008); the present cyclic voltammetry findings confirm that this input also causes immediate dopamine release from the projection to nucleus accumbens, consistent with evidence that dendritic dopamine release is a correlate of dopaminergic impulse flow (Legault et al, 2000; Legault and Wise, 1999, 2001).

While cocaine MI established cocaine-conditioned place preferences in animals trained to self-administer cocaine $\mathrm{HCl}$, the preferences were significantly weaker than the preference established by cocaine $\mathrm{HCl}$ itself. This was not surprising; while the peripheral actions of cocaine MI and cocaine $\mathrm{HCl}$ each cause a brief surge in dopamine release in cocaine-experienced rats, cocaine $\mathrm{HCl}$ enhances and prolongs the elevation of extracellular dopamine by its unconditioned ability to block the central dopamine transporter (Wise et al, 2008). This finding underscores the fact that the rapid effects of cocaine $\mathrm{MI}$ and cocaine $\mathrm{HCl}$ in cocaine-experienced rats are conditioned effects, effects due to the fact that the peripheral effects of cocaine $\mathrm{HCl}$ have reliably preceded the drug's central effects during the animals training history. The fact that cocaine MI had no rewarding effect when tested in animals that had not first been trained to self-administer cocaine $\mathrm{HCl}$ adds further evidence on this point.

Because the ability of cocaine-predictive exteroceptive cues to trigger cocaine seeking becomes progressively stronger over several drug-free weeks following cocaine $\mathrm{HCl}$ training (Grimm et al, 2001), we assessed the effectiveness of the interoceptive cocaine MI cue at 7, 15, and 30 days after the end of self-administration training. Cocaine MI established stronger place preferences after these withdrawal periods, the strongest of these was comparable to the strength of the preferences established by cocaine $\mathrm{HCl}$ after one day of withdrawal. The peak effectiveness was seen in animals tested 2 weeks after the last training day, reminiscent of the middle and late Phase 2 withdrawal cravings of detoxifying cocaine addicts (Gawin and Kleber, 1986).

Because conditioned stimuli retain their effectiveness for some time in the absence of continued pairing with their unconditioned stimulus, the earning of these stimuli tends to prolong responding under extinction conditions (Skinner, 1933). In the case of extinction of cocaine-seeking, intravenous cocaine MI was only temporarily and slightly more effective than intravenous saline in prolonging extinction, presumably because it shares with saline some of the stimulus properties intravenous injections (Kiyatkin and Lenoir, 2011). For example, the pressure and temperature of the solutions were common to cocaine MI and saline, and each can serve as a cue. In addition, the resistance of the lever, any lever or pump noise, and the illumination of the cue light are common to the earning of cocaine MI and saline injections, and each comes to predict cocaine's central effects under self-administration conditions; cue light illumination, for one, is known to cause momentary activation of the dopamine system (Stuber et al, 2005). The presence of each of these cues could contribute to the fact that it takes weeks of repeated testing to extinguish a selfadministration habit under our conditions, even in the absence of the peripheral drug cue.

Despite the prolonged period in which extinction responding was superficially equivalent between the MIand saline-extinguished animals, intraperitoneal cocaine $\mathrm{HCl}$ and cocaine $\mathrm{MI}$ priming injections each triggered 
significantly greater reinstatement of responding in salineextinguished animals than in MI-extinguished animals. This suggests that the early effectiveness of the peripheral drug cue may contribute importantly to temporary lapses, lapses where the sampling of cocaine itself stimulates further cocaine craving (Jaffe et al, 1989). Environmental stimuli associated with prior drug use are a major source of renewed drug-craving and -seeking in detoxified individuals (Childress et al, 1986; Stewart and Eikelboom, 1987), and the extinction of cue effectiveness by repeated cue exposure in the absence of drug has been used as an adjunct to treatment (McLellan et al, 1986). However, cue-exposure therapies have had limited success to date (Conklin and Tiffany, 2002; Marlatt, 1990; Myers and Carlezon, 2010), partly because of the ease with which the cues and context of the clinic are differentiated from those in the drug-taking environment (Bouton, 2002; Marlatt, 1990) and partly because external cues cause much weaker cocaine cravings than do the stimulus properties of the drug itself (de Wit and Stewart, 1981). Extinction of the association between the peripheral and central effects of cocaine offers a recently explored approach to cue-exposure therapy (Mihindou et al, 2011; Xue et al, 2012); repeated exposure to cocaine MI would appear to offer the most effective way to differentiate the peripheral stimulus properties of cocaine from its habit-forming central effects.

While footshock caused significant reinstatement of cocaine-trained lever-pressing, footshock-induced reinstatement resulting from cocaine MI substitution did not differ significantly from that resulting from saline substitution. This was somewhat surprising, inasmuch as repeated cocaine $\mathrm{HCl}$ priming before extinction trials with saline substitution attenuates stress-induced extinction (Mihindou et al, 2011). An 'interoceptive-conditioning hypothesis' is offered to explain the effect of this form of extinction treatment on stress-induced reinstatement; this hypothesis (Shaham and Stewart, 1995; Ahmed and Koob, 1997) postulates that interoceptive cues triggered by cocaine are similar to those triggered by footshock stress. Extinguishing only the peripheral interoceptive cues of cocaine using cocaine MI in this study failed to alter stress-induced reinstatement of cocaine-seeking, suggesting that the commonality between the interoceptive cues of cocaine and cues resulting from footshock, it is a commonality between the central and not the peripheral effects of the two treatments. The known common central effect of both stress (Shaham and Stewart, 1995) and cocaine (Hurd et al, 1988) is elevated dopamine overflow in the forebrain. While cocaine MI also increases forebrain dopamine overflow in cocaine-experienced rats, it is much weaker than cocaine $\mathrm{HCl}$ in this regard (Wise et al, 2008), and this may explain why extinction with substitution of cocaine MI has no greater effect on stress-induced reinstatement than does extinction with substitution of saline.

\section{ACKNOWLEDGEMENTS}

This work was supported by the Intramural Research Program of the National Institutes of Health and by NIH Grant R01DA025890 to JFC. We thank Drs Patricio O’Donnell and Rose-Marie Karlsson for providing animals with a history of cocaine self-administration for the voltammetry component of the study.

\section{DISCLOSURE}

The authors declare no conflict of interest.

\section{REFERENCES}

Ahmed SH, Koob GF (1997). Cocaine- but not food-seeking behavior is reinstated by stress after extinction. Psychopharmacology 132: 289-295.

Bouton ME (2002). Context, ambiguity, and unlearning: sources of relapse after behavioral extinction. Biol Psychiatry 52: 976-986.

Childress AR, McLellan AT, O'Brien CP (1986). Abstinent opiate abusers exhibit conditioned craving, conditioned withdrawal and reductions in both through extinction. $B r J$ Addict 1981: 655-660.

Conklin CA, Tiffany ST (2002). Applying extinction research and theory to cue-exposure addiction treatments. Addiction (Abingdon, England) 97: 155-167.

de Wit H, Stewart J (1981). Reinstatement of cocaine-reinforced responding in the rat. Psychopharmacology 75: 134-143.

de Wit H, Wise RA (1977). Blockade of cocaine reinforcement in rats with the dopamine receptor blocker pimozide, but not with the noradrenergic blockers phentolamine or phenoxybenzamine. Can J Psychol 31: 195-203.

Fouriezos G, Randall D (1997). The cost of delaying rewarding brain stimulation. Behav Brain Res 87: 111-113.

Gawin FH, Kleber HD (1986). Abstinence symptomatology and psychiatric diagnosis in cocaine abusers. Clinical observations. Archiv Gen Psychiatry 43: 107-113.

Grimm JW, Hope BT, Wise RA, Shaham Y (2001). Incubation of cocaine craving after withdrawal. Nature 412: 141-142.

Hurd YL, Kehr J, Ungerstedt U (1988). In vivo microdialysis as a technique to monitor drug transport: correlation of extracellular cocaine levels and dopamine overflow in the rat brain. J Neurochem 51: 1314-1316.

Jaffe J, Cascella NG, Kumor KM, Sherer MA (1989). Cocaineinduced cocaine craving. Psychopharmacology 97: 59-64.

Kiyatkin EA, Lenoir M (2011). Intravenous saline injection as an interoceptive signal in rats. Psychopharmacology (Berlin) 217: 387-396.

Legault M, Rompré P-P, Wise RA (2000). Chemical stimulation of the ventral hippocmpus elevates nucleus accumbens dopamine by activating dopaminergic neurons of the ventral tegmental area. J Neurosci 20: 1635-1642.

Legault M, Wise RA (1999). Injections of $\mathrm{N}$-methyl-D-aspartate into the ventral hippocampus increase extracellular dopamine in the ventral tegmental area and nucleus accumbens. Synapse 31: 241-249.

Legault M, Wise RA (2001). Novelty-evoked elevations of nucleus accumbens dopamine: dependence on impulse flow from the ventral subiculum and glutamatergic neurotransmission in the ventral tegmental area. Eur J Neurosci 13: 819-828.

Marlatt GA (1990). Cue exposure and relapse prevention in the treatment of addictive behaviors. Addict Behav 15: 395-399.

McLellan AT, Childress AR, Ehrman R, O'Brien CP, Pashko S (1986). Extinguishing conditioned responses during opiate dependence treatment turning laboratory findings into clinical procedures. J Subst Abuse Treat 3: 33-40.

Mihindou C, Vouillac C, Koob GF, Ahmed SH (2011). Preclinical validation of a novel cocaine exposure therapy for relapse prevention. Biol Psychiatry 70: 593-598.

Myers KM, Carlezon WA Jr. (2010). Extinction of drug- and withdrawal-paired cues in animal models: relevance to the treatment of addiction. Neurosci Biobehav Rev 35: 285-302. 
Porter-Stransky KA, Wescott SA, Hershman M, Badrinarayan A, Vander Weele CM, Lovic V et al (2011). Cocaine must enter the brain to evoke unconditioned dopamine release within the nucleus accumbens shell. Neurosci Lett 504: 13-17.

Renner KE (1964). Delay of reinforcement. Psychological Bull 61: 341-361.

Risner ME, Jones BE (1980). Intravenous self-administration of cocaine and norcocaine by dogs. Psychopharmacology 71: 83-89.

Roberts DCS, Corcoran ME, Fibiger HC (1977). On the role of ascending catecholaminergic systems in intravenous self-administration of cocaine. Pharmacol Biochem Behav 6: 615-620.

Shaham Y, Stewart J (1995). Stress reinstates heroin-seeking in drug-free animals: an effect mimicking heroin, not withdrawal. Psychopharmacology 119: 334-341.

Skinner BF (1933). 'Resistance to extinction' in the process of conditioning. J Gen Psychol 9: 420-429.

Stewart J, Eikelboom R (1987). Conditioned drug effects. In: Iversen LL, Iversen SD, Snyder SH (eds) Handbook of Psychopharmacology. Plenum Press: New York, NY, USA, pp 1-57.

Stuber GD, Wightman RM, Carelli RM (2005). Extinction of cocaine self-administration reveals functionally and temporally distinct dopaminergic signals in the nucleus accumbens. Neuron 46: 661-669.

Thomsen M, Hall FS, Uhl GR, Caine SB (2009a). Dramatically decreased cocaine self-administration in dopamine but not serotonin transporter knock-out mice. J Neurosci 29: 1087-1092.

Thomsen M, Han DD, Gu HH, Caine SB (2009b). Lack of cocaine self-administration in mice expressing a cocaine-insensitive dopamine transporter. J Pharmacol Exp Ther 331: 204-211.

Wise RA, Kiyatkin EA (2011a). Differentiating the rapid actions of cocaine. Nat Rev Neurosci 12: 479-484.

Wise RA, Kiyatkin EA (2011b). On the speed of cocaine. Nat Rev Neurosci 12: 700.

Wise RA, Wang B, You ZB (2008). Cocaine serves as a peripheral interoceptive conditioned stimulus for central glutamate and dopamine release. PLoS One 3: e2846.

Xue YX, Luo YX, Wu P, Shi HS, Xue LF, Chen C et al (2012). A memory retrieval-extinction procedure to prevent drug craving and relapse. Science 336: 241-245.

You ZB, Wang B, Zitzman D, Azari S, Wise RA (2007). A role for conditioned ventral tegmental glutamate release in cocaine seeking. J Neurosci 27: 10546-10555. 